J Pediatr. 2012 September ; 161(3): 434-440. doi:10.1016/j.jpeds.2012.02.047.

\title{
Biomarkers of Brain Injury in Neonatal Encephalopathy Treated with Hypothermia
}

An N. Massaro, MD1, Taeun Chang, MD $^{2}$, Nadja Kadom, MD $^{3}$, Tammy Tsuchida, MD, $\mathrm{PhD}^{2}$, Joseph Scafidi, DO ${ }^{2}$, Penny Glass, $\mathrm{PhD}^{4}$, Robert McCarter, ScD ${ }^{5}$, Stephen Baumgart, MD ${ }^{1}$, Gilbert Vezina, $\mathbf{M D}^{3}$, and Karin B. Nelson, $\mathbf{M D}^{2,6}$

${ }^{1}$ Department of Neonatology, Children's National Medical Center, Washington, DC

2Department of Neurology, Children's National Medical Center, Washington, DC

${ }^{3}$ Department of Neuroradiology, Children's National Medical Center, Washington, DC

${ }^{4}$ Department of Psychiatry and Behavioral Sciences, Children's National Medical Center, Washington, DC

${ }^{5}$ Department of Biostatistics and Informatics, Children's National Medical Center, Washington, DC

${ }^{6}$ National Institute of Neurological Disorders and Stroke, National Institutes of Health, Bethesda, MD

\section{Abstract}

Objective-To determine if early serum S100B and neuron-specific enolase (NSE) levels are associated with neuroradiographic and clinical evidence of brain injury in newborns with encephalopathy.

Study design-Patients who received therapeutic whole-body hypothermia were prospectively enrolled in this observational study. Serum specimens were collected at 0,12, 24, and 72 hours of cooling. S100B and NSE levels were measured by enzyme linked immunosorbent assay. Magnetic resonance imaging was performed in surviving infants at 7-10 days of life. Standardized neurologic examination was performed by a child neurologist at 14 days of life. Multiple linear regression analyses were performed to evaluate the association between S100B and NSE levels and unfavorable outcome (death or severe magnetic resonance imaging injury/significant neurologic deficit). Cutoff values were determined by receiver operating curve analysis.

Results-Newborns with moderate to severe encephalopathy were enrolled $(\mathrm{n}=75)$. Median $\mathrm{pH}$ at presentation was 6.9 (range, 6.5-7.35), and median Apgar scores of 1 at 1 minute, 3 at 5 minutes, and 5 at 10 minutes. NSE and S100B levels were higher in patients with unfavorable outcomes across all time points. These results remained statistically significant after controlling for covariables, including encephalopathy grade at presentation, Apgar score at 5 minutes of life, initial $\mathrm{pH}$, and clinical seizures.

Conclusion-Elevated serum S100B and NSE levels measured during hypothermia were associated with neuroradiographic and clinical evidence of brain injury in encephalopathic newborns. These brain-specific proteins may be useful immediate biomarkers of cerebral injury severity.

Copyright () 2012 Mosby Inc. All rights reserved.

Reprint requests: An N. Massaro, MD, Children's National Medical Center, 111 Michigan Avenue, NW, Washington, DC 20010. anguyenm@cnmc.org.

The authors declare no conflicts of interest. 
Neonatal encephalopathy is a devastating cause of infant mortality and neurodevelopmental disability. ${ }^{1,2}$ Despite the therapeutic success of hypothermia, moderate to severely affected newborns continue to have a $30 \%-70 \%$ risk of death or disability. ${ }^{3-6}$ A key to improving outcome is the identification of early biomarkers of brain injury that can be used to direct interventions, gauge treatment effects, and provide prognostic information for parental counseling. There is no serum biomarker in current clinical use for neonatal encephalopathy, however.

Magnetic resonance imaging (MRI) is the gold standard for early recognition of neonatal brain injury, ${ }^{7}$ but has limited sensitivity for detection of brain injury in the first 24 hours of life,, 89 a critical period when key therapeutic decisions are made. Serum biomarkers measured in the first hours to days of life that relate to later MRI injury can provide earlier prognostic information to guide management.

$\mathrm{S} 100 \mathrm{~B}$ is a neurotrophic protein released in the setting of astrocytic injury. ${ }^{10}$ Neuronspecific enolase (NSE) is a marker of neuronal injury. ${ }^{11}$ These candidate serum biomarkers are elevated in other brain-injured populations, such as persons with traumatic brain injury ${ }^{12-14}$ and stroke. ${ }^{15,16}$ Investigations of these biomarkers in encephalopathic newborns have been limited. ${ }^{17-25}$

\section{Methods}

All patients referred to a level IIIC neonatal intensive care unit for therapeutic hypothermia were approached for this prospective observational study. Encephalopathic newborns were treated with whole-body hypothermia according to the National Institute of Child Health and Development's Neonatal Research Network protocol, with inclusion criteria according to established criteria (ie, gestational age $>36$ weeks, birth weight $>1800 \mathrm{~g}$, demonstrated metabolic acidosis and/or low Apgar scores, and clinical signs of moderate to severe clinical encephalopathy). ${ }^{4}$ Exclusion criteria included small for gestational age, a known or suspected chromosomal abnormality, and a major congenital anomaly, all of which could affect biomarker levels. ${ }^{26,27} \mathrm{~A}$ written information sheet explaining the study was given to the parents at the referral hospital by the transport team at the time of transfer. Parents of eligible participants provided initial verbal agreement for this minimal-risk study either in person (at time of transfer) or via telephone (if agreement was not confirmed and/or a parent not available at the bedside on admission). This was followed by written informed consent for all patients continuing in the secondary longitudinal aspect of the study. The study was approved by the Institutional Review Board, and a waiver of documentation of informed consent was obtained to allow for the initial verbal consent used at enrollment.

\section{S100B and NSE Determinations}

Blood specimens ( $1 \mathrm{~mL}$ ) were collected at 0 (initiation of hypothermia), 12, 24, and 72 hours of cooling from an indwelling umbilical arterial or venous line. Samples were refrigerated immediately and processed within 24 hours. The samples were centrifuged at $500 \mathrm{rpm}$, and the supernatants were stored at $-70^{\circ} \mathrm{C}$ to allow for later assay in bulk. Stored serum from specimens obtained for clinical purposes were used in the few cases where parents could not be initially reached for consent. Salvaged clinical specimens were likewise frozen at $-70^{\circ} \mathrm{C}$ as soon as possible after processing and within 24 hours of collection. S100B and NSE levels were determined from $25-\mu \mathrm{L}$ and $50-\mu \mathrm{L}$ serum aliquots, respectively, by sandwich enzyme-linked immunosorbent assay using a commercially available kit according to the manufacturer's instructions (International Point of Care, Toronto, Canada). High, medium, and low controls provided by the manufacturer were assayed with each kit for quality assurance. The coefficient of variation for interassay and 
intra-assay variability was $<10 \%$ for both measurements. Assays were performed in duplicate, and average results were used in our analysis.

MRI

MRI was performed according to clinical protocol in surviving infants at target age 7-10 days of life on a 1.5-T scanner (Signa; General Electric Healthcare, Milwaukee, Wisconsin). Standard sequences included sagittal and axial spin-echo T1, double-acquisition axial fastspin echo $\mathrm{T} 2$ proton density, coronal fast-spin echo $\mathrm{T} 2$, and axial diffusion-weighted images. Images were reviewed by 2 neuroradiologists (N.K. and G.V.) masked to clinical data and biomarker levels. Images were scored according to the scheme of Barkovich et al ${ }^{28}$ with deep nuclear gray injury assigned a basal ganglia (BG) score of $0-4$ and cortical/white matter injury assigned a watershed (WS) score of 0-5. Discrepancies in scoring were resolved by consensus. Patients were classified by severity (normal, BG and WS scores 0 ; mild-moderate, any BG score $<3$ and WS $<4$; severe, BG $\geq 3$ and WS $\geq 4$ or death before MRI).

\section{Neurologic Examination}

Surviving infants were examined by a neonatal neurologist who was masked to the clinical data, including MRI results and biomarker levels. Standardized examination with the AmielTison Neurological Assessment at term was performed on day of life 14 (or on the day of discharge if before 14 days). ${ }^{29}$ A significant neurologic deficit was defined as a major abnormality of consciousness (eg, stupor, coma), tone (eg, severe hypertonia or hypotonia), or sensory or autonomic function (eg, absent visual fixation or gag/suck/feeding autonomy, ventilator dependence).

\section{Statistical Analysis}

Descriptive statistics included standard measures of central tendency and variability for continuous data and frequencies for categorical variables. Analyses were performed to evaluate the association of the biomarkers with poor outcome, defined as (1) death or severe MRI-detected injury (Barkovich BG score>3 and/or WS score >4); or (2) death or significant neurologic deficit ascertained by clinical examination at 2 weeks of life. Both neuroradiographic and clinical outcomes were evaluated to demonstrate consistency of results.

Associations of biomarkers and outcomes were evaluated by longitudinal multiple linear regression models that controlled for baseline confounding variables. Longitudinal multiple linear regression is the standard method for analyzing continuous outcomes that are measured at multiple points during follow-up of each individual. This method, also known as cross-sectional time series, adjusts variance estimates to account for the correlation between repeated measurements on the same individual. S100B and NSE levels were logtransformed for normalization of data and entered as the dependent variable. Outcome group (ie, death/severe MRI injury or significant neurologic deficit as defined above), time of measurement, grade of encephalopathy at presentation, initial pH, Apgar score at 5 minutes, and history of clinical seizures at initiation of hypothermia were included in each model. Additional covariables, including birth weight, gestational age, sex, cesarean delivery, sentinel event at birth (ie, placental abruption, uterine rupture, maternal arrest, umbilical cord rupture/knot, tight nuchal cord, fetal bradycardia, or traumatic delivery), hour of life on cooling, initial base deficit, electrographic seizures, and Apgar scores at 1 and 10 minutes were evaluated as potential confounders and included in the model if their presence altered (by at least 10\%) the magnitude of the association between biomarker and outcome (as indicated by the regression coefficient of the independent variable of interest). This statistical approach was chosen for the obvious advantages a continuous outcome offers in 
regard to statistical power, and the rationale that the biomarkers (dependent variable) are measures of brain injury (independent variable) that occurred before, although detected via clinical/radiographic means after, biomarker measurement. Receiver operating curve (ROC) analysis was then performed from the raw data at the different time points to evaluate the sensitivity and specificity of alternative cutoff values. ROC area under the curve (AUC) values are presented as the parameter estimate, with values ranging from 0.5 (no predictive ability) to 1 (perfect discrimination of outcome).

Biomarker determinations were performed at 4 time points per subject, allowing for up to 300 observations to estimate effects over time. Accounting for missed time points (eg, patients who died before collection of all time points or specimens that were not collected or were insufficient for determination), we estimated 225 observations for inclusion in the models. This sample size provided at least $80 \%$ statistical power to detect moderate effect size (SD, 0.6-0.65) differences in biomarker levels between patients with severe neurologic impairment and those with nonsevere neurologic impairment. Statistical analyses were performed with Stata 11.0 (StataCorp, College Station, Texas).

\section{Results}

A total of 75 neonates (mean birth weight, $3.4 \pm 0.6 \mathrm{~kg}$; mean gestational age, $39 \pm 0.8$ weeks) with moderate to severe encephalopathy were enrolled over the 3-year period from May 2008 to April 2011. An additional 7 neonates met the eligibility criteria during the study period but were not enrolled due to either parent refusal $(n=5)$ or inability to obtain consent before patient demise $(n=2)$. Fourteen enrolled patients died either from natural progression of disease $(n=1)$ or withdrawal of care because of poor neurologic prognosis based on clinical and electrographic information $(n=13)$. MRI and Amiel-Tison Neurological Assessment were performed in all surviving infants at a median age of 8 days (range, 5-34 days) and 12 days (range, 5-23 days), respectively. Severe MRI injury was present in 14 patients (10 with severe BG injury, 2 with diffuse cortical injury, and 2 with global injury). Significant neurologic deficit was observed in 5 patients, all of whom had MRI evidence of injury. Clinical characteristics of the study population by outcome category are presented in Table I.

Our analysis included 256 S100B measurements and 227 NSE measurements. Serum S100B and NSE levels were higher in the adverse outcome groups (Figure 1). These differences remained significant after controlling for covariables, including time of measurement $(P<$. 001 in all models), grade of encephalopathy at presentation, initial pH, Apgar score at 5 minutes, history of clinical seizures at hypothermia entry, birth weight, gestational age, and sex. Corresponding ROCs are presented in Figure 2. For prediction of death or severe MRI abnormality, baseline S100B and NSE levels provided the best discrimination of outcome. In contrast, S100B and NSE levels at 72 hours were the best predictors of poor outcome assessed by clinical neurologic examination. AUC estimates for S100B and NSE in predicting death or severe MRI-detected injury at initiation of cooling were 0.786 (95\% CI, 0.669-0.917) and 0.786 (95\% CI, 0.670-0.913), respectively. AUC estimates for NSE for predicting death and significant neurologic deficit at 72 hours of cooling were 0.814 (95\% CI, 0.655-0.973) and 0.816 (95\% CI, 0.670-0.962), respectively.

Cutpoints selected from the ROC coordinates are presented in Table II. Cutoff values were selected to optimize overall predictive ability (ie, percent classified correctly). In addition, alternative baseline (initiation of cooling) cutpoints were selected for optimal specificity, given certainty of poor prognosis is important at this time point for directing care and consideration of experimental therapies. Unadjusted likelihood ratios are presented for the selected cutpoints. 


\section{Discussion}

Identifying neurologic biomarkers is important for improving outcomes after perinatal brain injury. Validated biomarkers can optimize neurotherapeutic trials by more accurately risk stratifying patients at entry and serving as surrogate outcomes. If they enter clinical care, biomarkers can be used to help guide therapy, assess treatment effects, and offer prognostic information for families. Substances that can be measured in accessible biological fluids offer advantages over current tools for assessing the degree of brain injury in this population. Most centers rely on clinical examination or Sarnat staging ${ }^{30}$ to identify patients needing therapy. However, clinical examination changes over time, is subjective, and often confounded by neuroactive medications and interference from medical support devices. The initial clinical examination was recently shown to be a less reliable predictor of outcome in infants treated with hypothermia. ${ }^{31}$ Electroencephalographic data, although a useful prognostic tool, ${ }^{32,33}$ requires equipment and interpretive expertise not available at many centers. The emerging simplified amplitude integrated electroencephalogram tool was recently demonstrated by us and others to have limited early predictive value in infants treated with hypothermia. ${ }^{34,35}$ Even though specificity and positive predictive value improve after the first 48 hours of life, this improvement coincides with a decrease in sensitivity (approximately 50\% at rewarming) for identifying infants with adverse outcome. ${ }^{35}$ MRI, although predictive of outcome, ${ }^{28,36-39}$ has limited value in the first 24 hours of life ${ }^{8,9}$ and is restricted by the impracticability of transporting a critically ill neonate for imaging. Thus, there is a need for markers of brain injury that can be reliably measured and objectively interpreted. Data from this study suggest that elevated serum S100B and NSE are associated with brain injury evident during the neonatal period by either MRI findings or persistent neurologic abnormalities at 2 weeks. This association with outcome is independent of baseline characteristics and clinical assessment of encephalopathy at presentation.

S100B is a calcium-binding protein concentrated in astroglial cells of the central nervous system. Although its biological function has not been fully elucidated, S100B is neurotrophic at physiologic concentrations and neurotoxic at high concentrations. ${ }^{10,40}$ Supraphysiological concentrations have been described in the setting of acute traumatic brain injury ${ }^{12-14}$ and stroke. ${ }^{15,16} \mathrm{~S} 100 \mathrm{~B}$ is useful as a biomarker because of its relative ease and reproducibility of measurement, ready detectability in a variety of biologic fluids (eg, serum), and potential for longitudinal monitoring given its short (1 hour) half-life. ${ }^{40}$ Its utility has been evaluated in small studies of infants with neonatal encephalopathy, with conflicting results. ${ }^{17,18,20,23,24}$ This variability in findings might be attributable to the limited sample sizes, rarity of moderate or severe encephalopathy and adverse outcome in the study groups, and variable measurement times that characterize the majority of previous studies. Our data demonstrate that S100B (and NSE) levels change significantly over the first 24 hours of life, making group comparisons of measurements taken at nonuniform time points across subjects difficult to interpret. Specifying a narrow time window for comparable measurements is critical when evaluating the predictive ability of dynamic protein levels. Our results provide evidence that S100B reflects the extent of brain injury in infants with encephalopathy and provides predictive values at specific time points relevant to clinical practice.

NSE is a glycolytic enzyme concentrated in the cytoplasm of neurons and released in the setting of cell death. ${ }^{11}$ It has been studied extensively in pediatric traumatic brain injury, ${ }^{12-14}$ but only a few studies have been conducted in infants with encephalopathy. Several investigations have demonstrated an association between cerebrospinal fluid (CSF) NSE and severity of encephalopathy after asphyxia, as well as prediction of later neurodevelopmental outcome. ${ }^{19,22,41}$ The utility of a CSF biomarker is limited, however, 
because CSF it is not routinely sampled in infants presenting with encephalopathy, and indeed sampling is often contraindicated in the most critically ill patients. NSE measured from serum has also been evaluated, but with conflicting results.

We have evaluated S100B and NSE as potential biomarkers of brain injury in encephalopathic newborns undergoing hypothermia. Because hypothermia has emerged as the only proven effective neuroprotective therapy for newborns with encephalopathy, ${ }^{3-6}$ investigations into future therapeutic interventions in this population will be performed as adjuvants to cooling (ie, "hypothermia plus" trials). Thus, it is essential that studies evaluating potential biomarkers be performed in the setting of hypothermia. Validated biomarkers can then be used to identify patients who may benefit from adjuvant therapies or possible variations in hypothermia protocols.

Some limitations of this study should be acknowledged. To establish whether these potential biomarkers offer additional information over baseline characteristics or clinical variables assessable at the bedside, potential confounding variables were entered into the multiple regression models. The covariables explored might not represent all important variables that could be related to outcome. Likewise, fully accounting for all factors that could possibly have different effects on biomarker levels among subjects was not possible. It is possible that elevated S100B levels in infants with poor outcome are related to overwhelming systemic disease rather than specific for brain injury, given that infants with encephalopathy often present with multiorgan disease and that extraneural sources of S100B (including muscle, kidney, heart, and adipose tissue) have been reported ${ }^{42}$ In addition, serum protein levels might not truly reflect extent of injury to the central nervous system, because these measurements can be affected by the integrity of the blood-brain barrier and other factors that control release of proteins into the periphery in the setting of brain injury. Finally, technical variables, such as time to processing, effect of hemolysis, and effect of temperature, may affect the reproducibility and reliability of results. In light of these limitations, and the fact that that neither biomarker demonstrated perfect discriminatory ability, identifying a single ideal biomarker may remain an elusive goal. Some investigators have proposed that examination of a biomarker panel for consistency of results indicating brain injury might improve the prognostic abilities of proteins considered individually. ${ }^{43}$

This study did not include a control group of healthy, non-encephalopathic infants.

However, because the primary goal was to evaluate whether these biomarkers could identify infants with significant brain injury among at-risk infants, including a healthy control group was not necessary for our study aims. Serum levels in our overall population were higher than normative values reported from healthy newborns on the first day of life in previous studies (ie, S100B, $0.68 \pm 0.29 \mathrm{ng} / \mathrm{mL}^{44}$; NSE, $21 \pm 5.3 \mathrm{ng} / \mathrm{mL}^{21}$ ).

Specifying definitions of neuroradiographic and clinical adverse outcomes was an important aspect of this study. These short-term outcomes are surrogates for later significant neurologic disability. Although there is clear evidence that severe MRI-detected abnormalities are highly predictive of later neurologic deficits, ${ }^{28,36-39}$ the predictive value may be subject to variability due to differences in imaging protocols (ie, timing of acquisition, image parameters and sequences used), as well as in interrater reliability of the neuroradiologists' interpretation. Significant neurologic deficit 2 weeks after insult was evaluated as a second clinical endpoint. The definition used in this study describes a severe degree of neurologic devastation, a phenotype highly associated with disability later in life. ${ }^{29,45}$ There was clear overlap between these outcomes, because all patients with significant neurologic deficit had injury detected on MRI. Likewise, all patients with severe MRI-detected injury had abnormalities on neurologic examination, although not all met the defined criteria for significant deficit. The findings for both neuroradiographic and clinical 
outcomes indicate that S100B and NSE are associated with significant brain injury. Clearly, some patients that did not meet these criteria may develop neurologic impairment later in life. Further work is needed, and is ongoing as a secondary aim of this study, to correlate S100B and NSE levels with long-term outcome.

\section{Acknowledgments}

We thank Jianping (James) He, MS for data management and statistical support and Jennifer Teng, MS for assistance with specimen processing and data collection.

Supported by the Pediatric Clinical Research Scholars Award (5K12RR17613-05 to A.M.), the Clinical and Translational Science Institute at Children's National Medical Center (1KL2RR031987-01 to A.M.), and the National Institute of Neurological Disorders and Stroke (NIH NINDS 1K08NS073793 to J.S.).

\section{Glossary}

$\begin{array}{ll}\text { AUC } & \text { Area under the curve } \\ \text { BG } & \text { Basal ganglia } \\ \text { CSF } & \text { Cerebrospinal fluid } \\ \text { MRI } & \text { Magnetic resonance imaging } \\ \text { NSE } & \text { Neuron-specific enolase } \\ \text { ROC } & \text { Receiver operating curve } \\ \text { WS } & \text { Watershed }\end{array}$

\section{References}

1. Dilenge ME, Majnemer A, Shevell MI. Long-term developmental outcome of asphyxiated term neonates. J Child Neurol. 2001; 16:781-92. [PubMed: 11732762]

2. Shankaran S, Woldt E, Koepke T, Bedard MP, Nandyal R. Acute neonatal morbidity and long-term central nervous system sequelae of perinatal asphyxia in term infants. Early Hum Dev. 1991; 25:135-48. [PubMed: 1713544]

3. Gluckman PD, Wyatt JS, Azzopardi D, Ballard R, Edwards AD, Ferriero DM, et al. Selective head cooling with mild systemic hypothermia after neonatal encephalopathy: multicentre randomised trial. Lancet. 2005; 365:663-70. [PubMed: 15721471]

4. Shankaran S, Laptook AR, Ehrenkranz RA, Tyson JE, McDonald SA, Donovan EF, et al. Wholebody hypothermia for neonates with hypoxic-ischemic encephalopathy. N Engl J Med. 2005; 353:1574-84. [PubMed: 16221780]

5. Azzopardi D, Brocklehurst P, Edwards D, Halliday H, Levene M, Thoresen M, et al. The TOBY Study. Whole body hypothermia for the treatment of perinatal asphyxial encephalopathy: a randomised controlled trial. BMC Pediatr. 2008; 8:17. [PubMed: 18447921]

6. Jacobs SE, Morley CJ, Inder TE, Stewart MJ, Smith KR, McNamara PJ, et al. Whole-body hypothermia for term and near-term newborns with hypoxic-ischemic encephalopathy: a randomized controlled trial. Arch Pediatr Adolesc Med. 2011; 165:692-700. [PubMed: 21464374]

7. Ment LR, Bada HS, Barnes P, Grant PE, Hirtz D, Papile LA, et al. Practice parameter: neuroimaging of the neonate. Report of the Quality Standards Subcommittee of the American Academy of Neurology and the Practice Committee of the Child Neurology Society. Neurology. 2002; 58:1726-38. [PubMed: 12084869]

8. Barkovich AJ, Miller SP, Bartha A, Newton N, Hamrick SE, Mukherjee P, et al. MR imaging, MR spectroscopy, and diffusion tensor imaging of sequential studies in neonates with encephalopathy. AJNR Am J Neuroradiol. 2006; 27:533-47. [PubMed: 16551990] 
9. McKinstry RC, Miller JH, Snyder AZ, Mathur A, Schefft GL, Almli CR, et al. A prospective, longitudinal diffusion tensor imaging study of brain injury in newborns. Neurology. 2002; 59:82433. [PubMed: 12297561]

10. Goncalves CA, Leite MC, Nardin P. Biological and methodological features of the measurement of S100B, a putative marker of brain injury. Clin Biochem. 2008; 41:755-63. [PubMed: 18454941]

11. Kaiser E, Kuzmits R, Pregant P, Burghuber O, Worofka W. Clinical biochemistry of neuronspecific enolase. Clin Chim Acta. 1989; 183:13-31. [PubMed: 2548772]

12. Berger RP, Adelson PD, Pierce MC, Dulani T, Cassidy LD, Kochanek PM. Serum neuron-specific enolase, S100B, and myelin basic protein concentrations after inflicted and noninflicted traumatic brain injury in children. J Neurosurg. 2005; 103:61-8. [PubMed: 16122007]

13. Stalnacke BM, Bjornstig U, Karlsson K, Sojka P. One-year follow-up of mild traumatic brain injury: post-concussion symptoms, disabilities and life satisfaction in relation to serum levels of S-100B and neurone-specific enolase in acute phase. J Rehabil Med. 2005; 37:300-5. [PubMed: 16208863]

14. Vos PE, Lamers KJ, Hendriks JC, van Haaren M, Beems T, Zimmerman C, et al. Glial and neuronal proteins in serum predict outcome after severe traumatic brain injury. Neurology. 2004; 62:1303-10. [PubMed: 15111666]

15. Herrmann M, Ehrenreich H. Brain-derived proteins as markers of acute stroke: their relation to pathophysiology, outcome prediction and neuroprotective drug monitoring. Restor Neurol Neurosci. 2003; 21:177-90. [PubMed: 14530580]

16. Jauch EC, Lindsell C, Broderick J, Fagan SC, Tilley BC, Levine SR. Association of serial biochemical markers with acute ischemic stroke: the National Institute of Neurological Disorders and Stroke rt-PA Stroke Study. Stroke. 2006; 37:2508-13. [PubMed: 16960091]

17. Nagdyman N, Komen W, Ko HK, Muller C, Obladen M. Early biochemical indicators of hypoxicischemic encephalopathy after birth asphyxia. Pediatr Res. 2001; 49:502-6. [PubMed: 11264433]

18. Nagdyman N, Grimmer I, Scholz T, Muller C, Obladen M. Predictive value of brain-specific proteins in serum for neurodevelopmental outcome after birth asphyxia. Pediatr Res. 2003; 54:270-5. [PubMed: 12736385]

19. Thornberg E, Thiringer K, Hagberg H, Kjellmer I. Neuron-specific enolase in asphyxiated newborns: association with encephalopathy and cerebral function monitor trace. Arch Dis Child Fetal Neonatal Ed. 1995; 72:F39-42. [PubMed: 7743283]

20. Thorngren-Jerneck K, Alling C, Herbst A, Amer-Wahlin I, Marsal K. S100 protein in serum as a prognostic marker for cerebral injury in term newborn infants with hypoxic ischemic encephalopathy. Pediatr Res. 2004; 55:406-12. [PubMed: 14630979]

21. Celtik C, Acunas B, Oner N, Pala O. Neuron-specific enolase as a marker of the severity and outcome of hypoxic ischemic encephalopathy. Brain Dev. 2004; 26:398-402. [PubMed: 15275704]

22. Ezgu FS, Atalay Y, Gucuyener K, Tunc S, Koc E, Ergenekon E, et al. Neuron-specific enolase levels and neuroimaging in asphyxiated term newborns. J Child Neurol. 2002; 17:824-9. [PubMed: 12585722]

23. Tekgul H, Yalaz M, Kutukculer N, Ozbek S, Kose T, Akisu M, et al. Value of biochemical markers for outcome in term infants with asphyxia. Pediatr Neurol. 2004; 31:326-32. [PubMed: 15519113]

24. Maschmann J, Erb MA, Heinemann MK, Ziemer G, Speer CP. Evaluation of protein S-100 serum concentrations in healthy newborns and seven newborns with perinatal acidosis. Acta Paediatr. 2000; 89:553-5. [PubMed: 10852191]

25. Verdu Perez A, Falero MP, Arroyos A, Estevez F, Felix V, Lopez Y, et al. Blood neuronal-specific enolase in newborns with perinatal asphyxia. Rev Neurol. 2001; 32:714-7. (in Spanish). [PubMed: 11391504]

26. Florio P, Marinoni E, Di Iorio R, Bashir M, Ciotti S, Sacchi R, et al. Urinary S100B protein concentrations are increased in intrauterine growth-retarded newborns. Pediatrics. 2006; 118:e747-54. [PubMed: 16923924]

27. Netto CB, Portela LV, Ferreira CT, Kieling C, Matte U, Felix T, et al. Ontogenetic changes in serum S100B in Down syndrome patients. Clin Biochem. 2005; 38:433-5. [PubMed: 15820773] 
28. Barkovich AJ, Hajnal BL, Vigneron D, Sola A, Partridge JC, Allen F, et al. Prediction of neuromotor outcome in perinatal asphyxia: evaluation of MR scoring systems. AJNR Am J Neuroradiol. 1998; 19:143-9. [PubMed: 9432172]

29. Amiel-Tison C. Update of the Amiel-Tison neurologic assessment for the term neonate or at 40 weeks corrected age. Pediatr Neurol. 2002; 27:196-212. [PubMed: 12393130]

30. Sarnat HB, Sarnat MS. Neonatal encephalopathy following fetal distress: a clinical and electroencephalographic study. Arch Neurol. 1976; 33:696-705. [PubMed: 987769]

31. Gunn AJ, Wyatt JS, Whitelaw A, Barks J, Azzopardi D, Ballard R, et al. Therapeutic hypothermia changes the prognostic value of clinical evaluation of neonatal encephalopathy. J Pediatr. 2008; 152:55-8. [PubMed: 18154900]

32. Holmes G, Rowe J, Hafford J, Schmidt R, Testa M, Zimmerman A. Prognostic value of the electroencephalogram in neonatal asphyxia. Electro-encephalogr Clin Neurophysiol. 1982; 53:6072.

33. Obrecht R, Pollock MA, Evans S, Scott DF. Prediction of outcome in neonates using EEG. Clin Electroencephalogr. 1982; 13:46-9. [PubMed: 7067153]

34. Thoresen M, Hellstrom-Westas L, Liu X, de Vries LS. Effect of hypothermia on amplitudeintegrated electroencephalogram in infants with asphyxia. Pediatrics. 2010; 126:e131-9. [PubMed: 20566612]

35. Massaro AN, Tsuchida T, Kadom N, Glass P, Baumgart S, Chang T. aEEG evolution during therapeutic hypothermia and prediction of outcome in encephalopathic neonates. Neonatology. 2012 In press.

36. Steinman KJ, Gorno-Tempini ML, Glidden DV, Kramer JH, Miller SP, Barkovich AJ, et al. Neonatal watershed brain injury on magnetic resonance imaging correlates with verbal IQ at 4 years. Pediatrics. 2009; 123:1025-30. [PubMed: 19255035]

37. Miller SP, Ramaswamy V, Michelson D, Barkovich AJ, Holshouser B, Wycliffe N, et al. Patterns of brain injury in term neonatal encephalopathy. J Pediatr. 2005; 146:453-60. [PubMed: 15812446]

38. Foran A, Cinnante C, Groves A, Azzopardi DV, Rutherford MA, Cowan FM. Patterns of brain injury and outcome in term neonates presenting with postnatal collapse. Arch Dis Child Fetal Neonatal Ed. 2009; 94:F168-77. [PubMed: 18981034]

39. Belet N, Belet U, Incesu L, Uysal S, Ozinal S, Keskin T, et al. Hypoxic-ischemic encephalopathy: correlation of serial MRI and outcome. Pediatr Neurol. 2004; 31:267-74. [PubMed: 15464639]

40. Michetti F, Gazzolo D. S100B protein in biological fluids: a tool for perinatal medicine. Clin Chem. 2002; 48:2097-104. [PubMed: 12446464]

41. Garcia-Alix A, Cabanas F, Pellicer A, Hernanz A, Stiris TA, Quero J. Neuron-specific enolase and myelin basic protein: relationship of cerebrospinal fluid concentrations to the neurologic condition of asphyxiated full-term infants. Pediatrics. 1994; 93:234-40. [PubMed: 7510064]

42. Haimoto H, Hosoda S, Kato K. Differential distribution of immunoreactive S100-alpha and S100beta proteins in normal nonnervous human tissues. Lab Invest. 1987; 57:489-98. [PubMed: 3316838]

43. Bloomfield SM, McKinney J, Smith L, Brisman J. Reliability of S100B in predicting severity of central nervous system injury. Neurocrit Care. 2007; 6:121-38. [PubMed: 17522796]

44. Gazzolo D, Di Iorio R, Marinoni E, Masetti P, Serra G, Giovannini L, et al. S100B protein is increased in asphyxiated term infants developing intraventricular hemorrhage. Crit Care Med. 2002; 30:1356-60. [PubMed: 12072694]

45. Amess PN, Penrice J, Wylezinska M, Lorek A, Townsend J, Wyatt JS, et al. Early brain proton magnetic resonance spectroscopy and neonatal neurology related to neurodevelopmental outcome at 1 year in term infants after presumed hypoxic-ischaemic brain injury. Dev Med Child Neurol. 1999; 41:436-45. [PubMed: 10454226] 


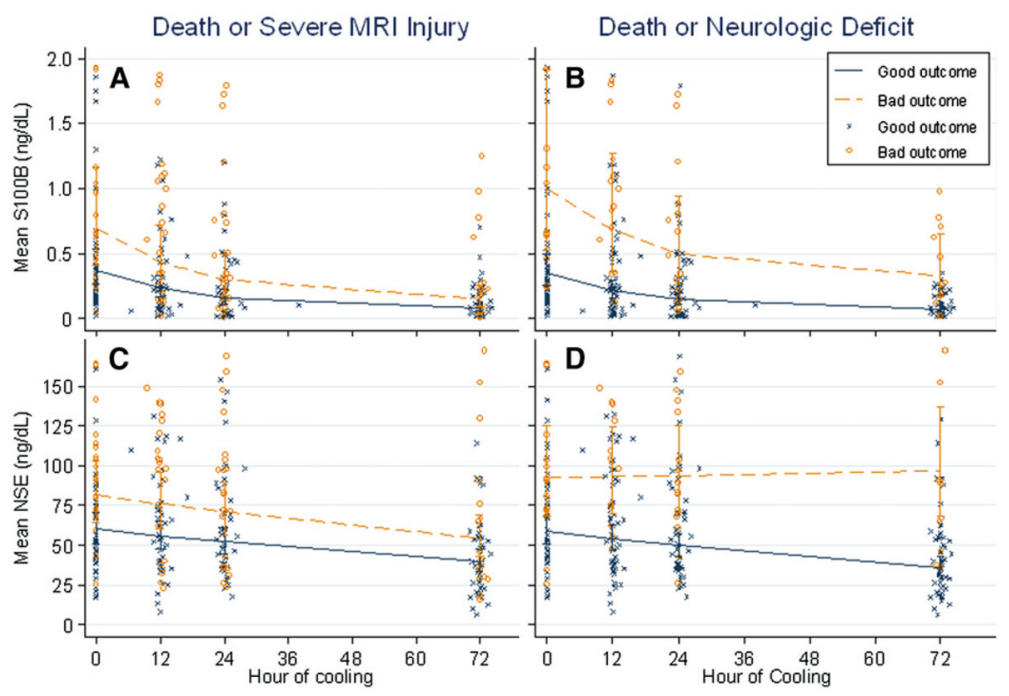

Figure 1.

Biomarker levels (A and B, S100B; C and D, NSE) by outcome category (death or severe MRI-detected injury and death or neurologic deficit). Regression fit lines for biomarker levels from infants with unfavorable (dashed line) and favorable (solid line) outcome are presented. Raw (unadjusted) data are shown in the overlying scatterplot. Error bars represent $95 \%$ CIs. 
A Death or Severe MRI Injury

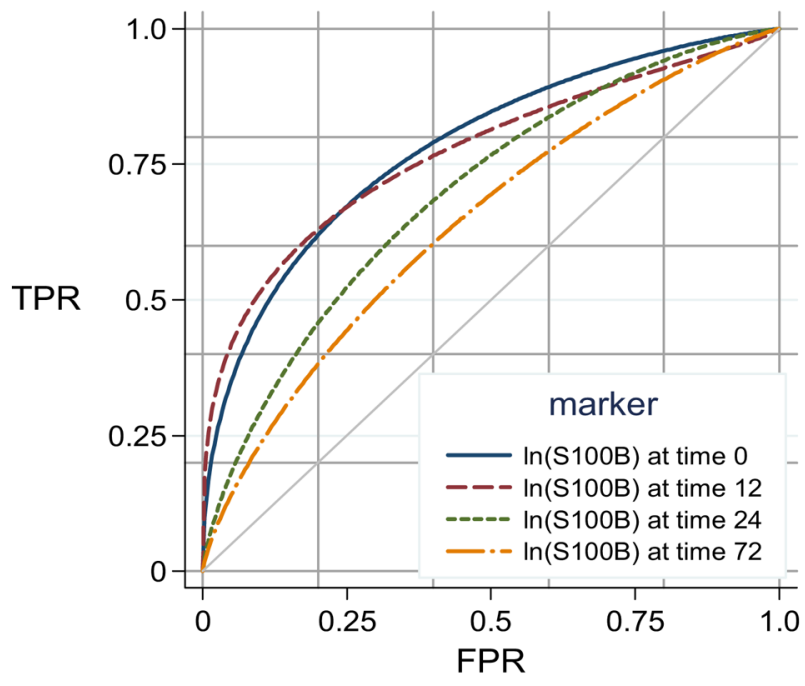

C Death or Severe MRI Injury

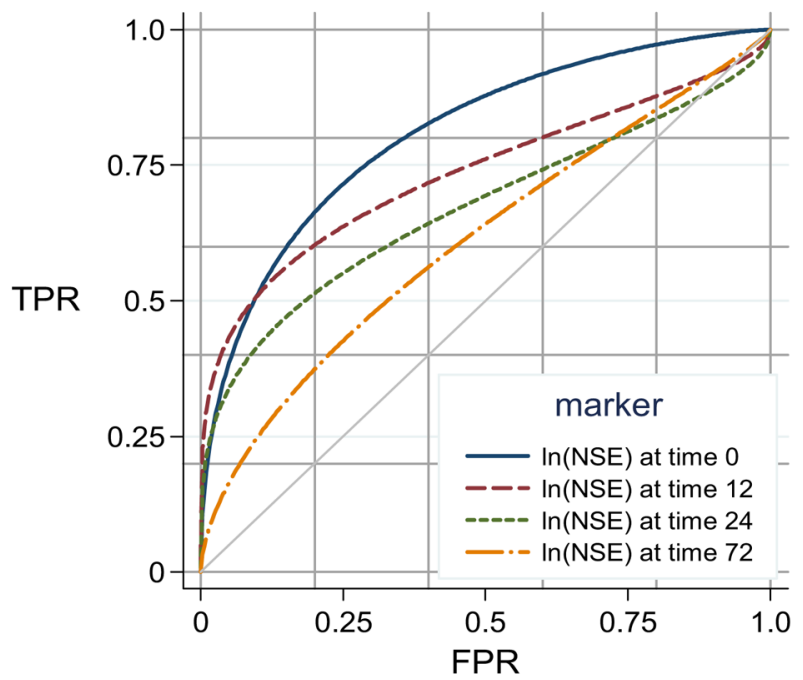

B Death or Neurological Deficit

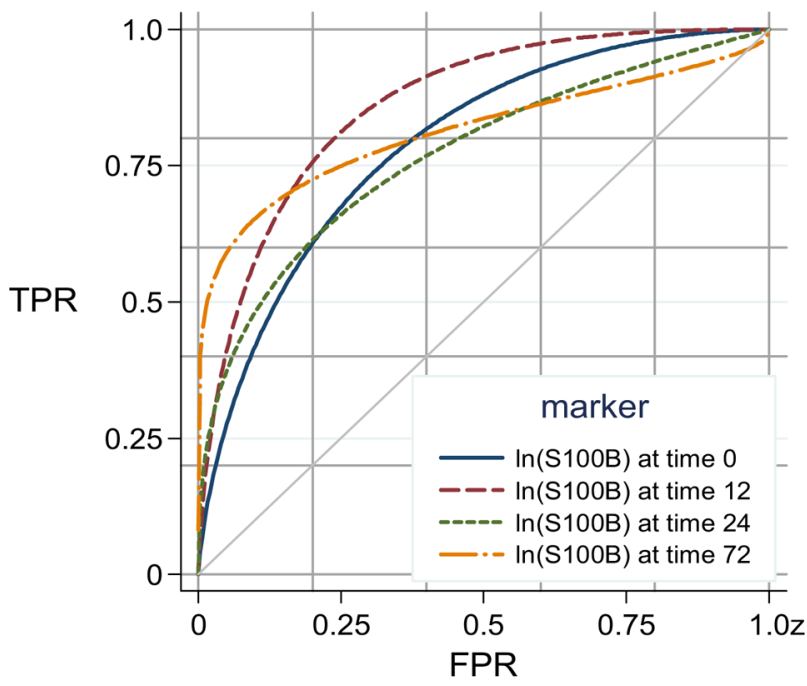

D Death or Neurological Deficit

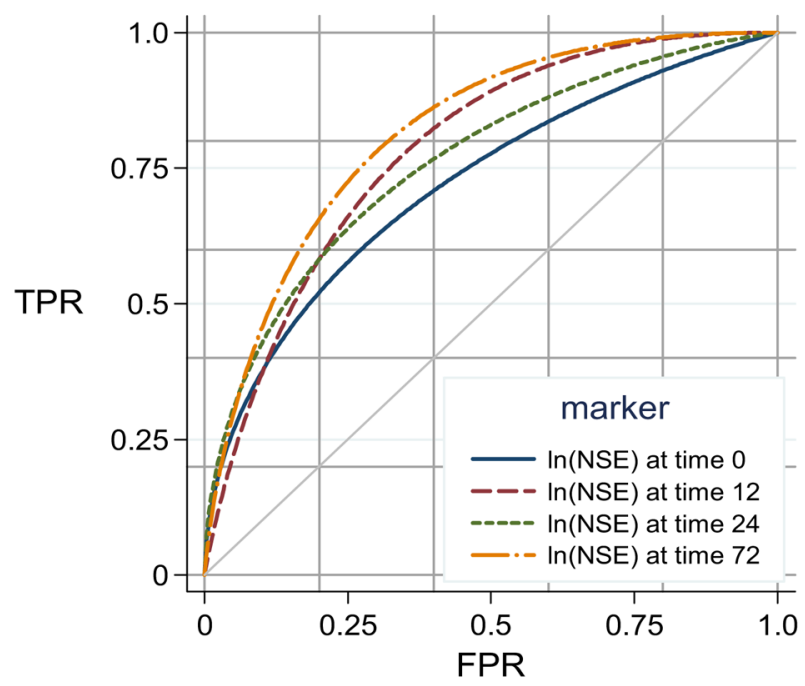

Figure 2.

ROC curves for $\mathbf{A}$ and B, S100 and C and D, NSE (C, D) and prediction of outcome. Each time point has a representative curve. Biomarker levels at 0 hours of cooling are the best discriminators of death or severe MRI-detected injury, and levels at 72 hours of cooling are the best discriminators of death or significant neurologic deficit. $T P R$, true-positive rate;

$F P R$, false-positive rate. 


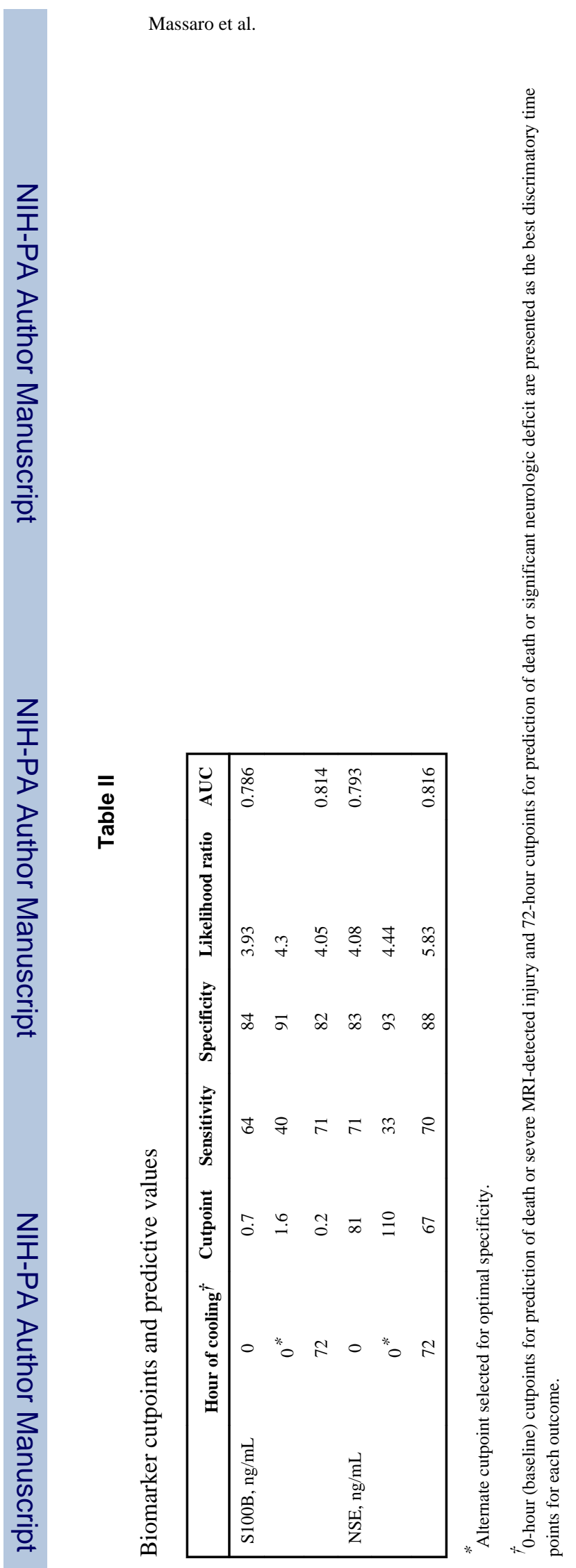

J Pediatr. Author manuscript; available in PMC 2013 September 01. 